OCCASIONAL REVIEW

\title{
Asbestos, asbestosis, and lung cancer: a critical assessment of the epidemiological evidence
}

\author{
P A Hessel, J F Gamble, J C McDonald
}

Thorax 2005;60:433-436. doi: 10.1136/thx.2004.037267

The question of whether lung cancer can be attributed to asbestos exposure in the absence of asbestosis remains controversial. Nine key epidemiological papers are reviewed in a point/counterpoint format, giving the main strengths and limitations of the evidence presented. Of the nine papers, two concluded that asbestosis was necessary and seven that it was not. However, the study design, nature and circumstances of exposure and method of analysis of the studies differed considerably, and none was considered definitive. It is concluded that, because of the relative insensitivity of chest radiography and the uncertain specificity of findings from histological examinations or computed tomography, it is unlikely that epidemiology alone can put either the strict scientific or practical medicolegal questions beyond doubt. It is probable that the issue may depend critically on asbestos fibre type, an aspect not so far addressed.

See end of article for authors' affiliations

Correspondence to: Professor J C McDonald, Department of

Occupational and

Environmental Medicine, National Heart and Lung Institute, Imperial College School of Medicine,

Dovehouse Street, London

SW3 6LY, UK;

c.mcdonald@imperial.ac. uk

Received

5 November 2004

Accepted

3 December 2004 he aim of this paper is to review the evidence in the important scientific and medicolegal controversy as to whether or not lung cancer can be attributed to asbestos exposure without radiographic evidence of asbestosis. In the absence of a definitive answer to this question, a balanced review may highlight areas of uncertainty and inform future research.

Nine frequently cited epidemiological papers were selected for discussion by consensus of the authors, one of whom (PAH) believes that radiographic evidence is necessary, one (JCMCD) who does not, and one (JFG) who is still undecided. Studies known to the authors comprised the starting point for the review and their reference lists were then scanned. This was supplemented by an electronic literature review focused on the more recent studies. Each study was evaluated to determine whether it provided substantive information related to the question. Studies that examined exposure-response relationships between lung cancer and asbestos exposure without considering asbestosis were not included. Such studies would be relevant to the debate only if they had demonstrated an increased risk of lung cancer at levels of exposure below those at which asbestosis was likely to develop. Studies in the rapidly developing field of molecular carcinogenesis were also not considered but may eventually be relevant to the debate.
$\mathrm{T}$
The authors of the two studies described in table 1 concluded that asbestosis is necessary. A summary of the strengths and limitations of each paper is given below. This is followed by similar treatment of the seven studies shown in table 2 which came to the opposite conclusion. We have adapted this somewhat legal approach in order to inform rather than reach a final verdict; indeed, the authors themselves continue to disagree. For the sake of brevity, the descriptions of the studies are minimal. The reader is referred to the original papers for additional detail.

Epidemiological studies suggesting that lung cancer cannot be attributed to asbestos exposure without radiographic evidence of asbestosis (table 1)

Sluis-Cremer and Bezuidenhout ${ }^{1}$

In a follow up study of 7318 white South African amphibole miners, 1165 died and 427 of these had post mortem examination. Of the 399 with information on smoking, the 35 who died from lung cancer were compared with the 364 who died from other causes. Exposure was not significant after fitting degree of asbestosis, but proportional mortality among those without asbestosis was not increased.

Strengths

- Histological confirmation of both lung cancer and asbestosis.

- Extensive fibre monitoring in South African asbestos industry.

- Well documented occupational, medical and smoking histories.

- Evidence that proportional mortality analyses were not biased by healthy worker effect.

Limitations

- Of 1165 deaths, only 427 (36.7\%) came to post mortem examination.

- Asbestosis might have been over-represented to obtain compensation.

- Pathologists may have looked harder for asbestosis in cases with lung cancer.

- Asbestosis assessed histologically without definition; radiographic evidence not considered.

- Asbestosis-a surrogate for exposure-was entered in the analysis before exposure variables which therefore could not be adequately evaluated. (A later supplemental analysis, however, found that most measures of exposure were significant when entered into the multivariate model before asbestosis ${ }^{2}$ ). 
Table 1 Epidemiological studies suggesting that lung cancer cannot be attributed to asbestos exposure without radiographic evidence of asbestosis

\begin{tabular}{llll}
\hline Reference & Study design & Subjects & Main findings \\
\hline Sluis-Cremer' & Cohort mortality; & 35 lung cancers by autopsy and 364 & No evidence of lung cancer excess in men without \\
Hughes $^{3}$ & case-referent analysis & other causes in 7318 amphibole miners & histological asbestosis \\
& Cohort mortality & 646 asbestos cement workers $>20$ years & Lung cancer SMR only increased significantly in men \\
& & from hith pleural or parenchymal changes & ire \\
\hline
\end{tabular}

SMR, standardised mortality ratio.

Hughes and Weill ${ }^{3}$

Workers in two asbestos cement plants $(\mathrm{n}=839)$ were followed from 1969 to 1983 . The standardised mortality ratios (SMRs) were $1.05(\mathrm{n}=10)$ for those without radiographic abnormalities, $1.78(\mathrm{n}=4)$ for those with profusion readings of $0 / 1$, and $4.33(\mathrm{n}=9)$ for those with readings $\geqslant 1 / 0$.

\section{Strengths}

- Smoking and asbestos exposure data were available.

- Chest radiographs in 1969 had shown that small opacities were related to cumulative exposure and smoking.

\section{Limitations}

- Only 25 lung cancer deaths including four with a reading of $0 / 1$ (the study thus had very low power).

- Even a few changes between $0 / 1$ and $1 / 0$ would have changed the result.

- More smokers among men with small opacities (83\%) than among those without (73\%).

- Cumulative exposure also higher in those with small opacities (177 mpcf.year) than in those without (123 mpcf.year).

\section{Epidemiological studies suggesting that lung cancer can be attributed to asbestos exposure without radiographic evidence of asbestosis (table 2) Martischnig et al ${ }^{4}$}

A history of jobs involving asbestos exposure was compared for 201 cases of lung cancer and 201 hospital controls. None of the subjects had asbestosis based on physical and radiological examinations and pulmonary function tests. Of the 201 men with lung cancer, $58(29 \%)$ gave a history of asbestos exposure compared with 29 (14\%) of controls $(\mathrm{p}<0.001)$, producing an overall odds ratio of 2.35 (95\% CI
1.39 to 3.97) for asbestos exposure among cases stratified by smoking category.

\section{Strengths}

- Asbestosis excluded from case series by radiographic and pulmonary function tests.

- Structured occupational and smoking history recorded by single interviewer.

- Exposure to asbestos in sample of 10 cases was probably substantial.

- Objective was direct test of hypothesis.

\section{Limitations}

- Comparability and validity of hospital controls open to question.

- Criteria for diagnosis of asbestosis not specified.

- Work histories not recorded blindly.

- Resected lung tissue and tumours examined for cell type and fibre burden, but not for fibrosis.

- No assessment made of duration or intensity of asbestos exposure.

\section{Liddell and McDonald ${ }^{5}$}

The mortality of two cohorts of asbestos miners and millers was compared for those with normal or less than normal radiographs. The radiographs were taken at varying periods before the end of follow up. For the first cohort, the SMR for lung cancer for those with normal radiographs was 1.08, and for those with less than normal radiographs it was 3.50. The relative risks for lung cancer were 2.88 and 20.7 among those with small opacities and large opacities, respectively, compared with those with normal radiographs or without exposure.

Table 2 Epidemiological studies suggesting that lung cancer can be attributed to asbestos exposure without radiographic evidence of asbestosis

\begin{tabular}{|c|c|c|c|}
\hline Reference & Study design & Subjects & Main findings \\
\hline Martischnig $^{4}$ & Case-referent & $\begin{array}{l}201 \text { cases of lung cancer without asbestosis; } \\
201 \text { age/sex/area-matched hospital referents }\end{array}$ & $\begin{array}{l}\text { Increased odds ratio at all levels of smoking for } \\
\text { history of asbestos exposure }\end{array}$ \\
\hline Liddell $^{5}$ & Cohort mortality & $\begin{array}{l}4559 \text { chrysotile miners and millers with } \\
\text { chest } x \text { ray }\end{array}$ & $\begin{array}{l}\text { Of } 52 \text { excess cases of lung cancer, } 33 \text { showed no } \\
\text { small opacities; } 3 \text {-fold RR of cases with compared } \\
\text { with those without small opacities }\end{array}$ \\
\hline Karjalainen $^{6 *}$ & Case-referent & $\begin{array}{l}108 \text { lung cancer patients with and without } \\
\text { asbestosis }\end{array}$ & $\begin{array}{l}\text { Lower lobe tumours predominate even in absence of } \\
\text { fibrosis }\end{array}$ \\
\hline Hillerdal $^{8}$ & Cohort mortality & $\begin{array}{l}1596 \text { men with pleural plaques identified in } \\
\text { health surveys, 1970-85 }\end{array}$ & $\begin{array}{l}\text { RR for lung cancer increased significantly in men } \\
\text { with and without small opacities }(1.6 v 1.4)\end{array}$ \\
\hline Wilkinson ${ }^{9}$ & Case-referent & $\begin{array}{l}271 \text { cases of lung cancer and } 678 \text { hospital } \\
\text { referents }\end{array}$ & $\begin{array}{l}\text { RR for lung cancer increased significantly in men } \\
\text { with and without small opacities }\end{array}$ \\
\hline Finkelstein $^{10}$ & Cohort mortality & $\begin{array}{l}143 \text { Ontario asbestos cement workers, } \\
20 \text { with asbestosis }\end{array}$ & $\begin{array}{l}\text { Lung cancer SMR for men with asbestosis } 9.96 \text { (95\% } \\
\mathrm{Cl} 2.71 \text { to } 25.5) \text {; without } 5.53 \text { (2.86 to } 9.66)\end{array}$ \\
\hline de Klerk" & $\begin{array}{l}\text { Cohort mortality; } \\
\text { case-referent analysis }\end{array}$ & $\begin{array}{l}55 \text { cases of lung cancer and } 841 \text { referents for } \\
\text { a cohort of } 6910 \text { Australian crocidolite miners }\end{array}$ & $\begin{array}{l}\text { Significantly increased RR for lung cancer in subjects } \\
\text { with and without asbestosis }\end{array}$ \\
\hline
\end{tabular}




\section{Strengths}

- All data on mortality to 1975 and radiographic changes before 1996 already recorded.

- Chest radiographs scored blindly and independently by up to six readers.

- Analysis confined to men who had ceased work before 1966.

\section{Limitations}

- Many of the radiographs were from men taken some years before death.

- The all cause SMR for men with normal radiographs in the first cohort was 1.20 and for the second cohort was 0.84 , suggesting selection bias.

- The authors stated that those who died were preferentially classified in cohort one, suggesting the lung cancer excess was unrelated to chrysotile exposure.

\section{Karjalainen et alo}

Among 108 lung cancer patients, the lobe of origin of the tumours was examined in relation to an occupational history of asbestos exposure. Asbestos exposure was more common among those with lower lobe tumours, even after excluding those with histological evidence of interstitial fibrosis (relative risk $=2.4$ ). The relative risk of a lower lobe tumour in relation to a fibre concentration of $\geqslant 1 \times 10^{6}$ fibre/g was 1.7 (95\% CI 1.1 to 2.5$)$.

\section{Strengths}

- Work and smoking histories taken before lobectomy were assessed blindly by two industrial hygienists.

- Lung tissue analysed for fibre content and degree of fibrosis.

\section{Limitations}

- The few cases with fibrosis confirmed radiologically all had lower lobe tumours.

- Almost all the cases with fibrosis were in the highest fibre concentration, thus invalidating the association between asbestos exposure alone and lower lobe tumours among those without fibrosis.

- As all the non-smokers had low fibre counts, it is unlikely that the effects of smoking and exposure could be separated statistically.

- Fibrosis in all parts of the lung could not be excluded in exposed cases.

\section{Hillerdal ${ }^{8}$}

A group of 1596 men with radiographic evidence of pleural plaques was identified through a population survey. Those with radiographic evidence of asbestosis had a relative risk of lung cancer of 2.3. Those without asbestosis had a relative risk of 1.4. In all, there were 50 deaths from bronchial carcinoma and nine from mesothelioma; all of the former were smokers or ex-smokers. The estimated average intensity of asbestos exposure was correlated with the presence of small radiographic opacities but duration was not.

\section{Strengths}

- Subjects with plaques recalled for full size radiographs and detailed work history.

- Asbestosis defined as prevalence of small opacities $\geqslant 1 / 0$.

\section{Limitations}

- Radiograph reading procedure not described.

- The time between first radiograph, last radiograph, and diagnosis/death was not stated.

- Some with pleural plaques may have had, or later have developed, asbestosis that had not previously been detected radiographically.

\section{Wilkinson et al ${ }^{9}$}

Patients admitted to hospital with lung cancer $(\mathrm{n}=271)$ were compared with 678 other patients, most with respiratory $(\mathrm{n}=279)$ or cardiac $(\mathrm{n}=399)$ diagnoses. The odds ratio for asbestos exposure and lung cancer was 2.03 for those with profusion readings $\geqslant 1 / 0$ and 1.56 for those with lower readings. Both odds ratios were adjusted for age, sex, smoking history, and area of referral, and both exceeded the unadjusted odds ratio of 1.49 for the total group.

\section{Strengths}

- Detailed work and smoking histories taken blindly.

- Classification scheme for asbestos exposure validated previously.

- Radiographs scored blindly and independently by three experienced readers.

- Radiographic evidence of tumour blacked out in cases and a similar number of controls.

\section{Limitations}

- Possible bias from selection of cases and referents in a hospital-based comparison.

- The odds ratio for asbestos exposure in the absence of irregular opacities was not significant when self-reported exposures were used, as opposed to those assessed objectively from the work histories.

\section{Finkelstein ${ }^{10}$}

Asbestos cement workers with available radiographs $(\mathrm{n}=143)$ were followed for mortality. The SMR for lung cancer among the 123 without radiographic evidence of asbestosis was 5.53 compared with 9.96 among the 20 with asbestosis. The similarity between the SMR for smokers (6.44) and non-smokers (6.18) was attributed to the misclassification of three non-smokers as smokers.

\section{Strengths}

- The cohort, though small, was heavily exposed to crocidolite, chrysotile and silica.

- Chest radiographs scored blindly by one 'B' reader.

\section{Limitations}

- The internal regression analysis found that lung cancer was not related to asbestos exposure, smoking, or asbestosis, but was related to age.

- The extraordinarily high all-cause SMR points to serious selection bias in assembly of the study group.

\section{De Klerk et al ${ }^{11}$}

Fifty five patients with lung cancer from a cohort of Wittenoom crocidolite workers were matched to 841 controls. When smoking, logarithm of asbestos exposure, and small opacities were analysed simultaneously by logistic regression, all three variables were significantly and independently associated with lung cancer. 


\section{Strengths}

- Radiographs selected close to date of diagnosis of cases and scored by up to 13 readers.

- Exposure estimated from employment records and fibre counts.

- Smoking histories obtained from next of kin or hospital records.

\section{Limitations}

- Radiograph readers probably not blinded to case-control status.

- Controls required to have ceased exposure at time of diagnosis of the case, reducing their eventual exposure.

- Comparability of crudely quantified smoking data open to question.

- No explanation for use of log of cumulative exposure as opposed to other metrics.

\section{Other considerations}

In the UK, at least, there are reasons for thinking that asbestos related lung cancer is underdiagnosed and undercompensated. In a review of 31 cohort studies of male asbestos workers published in 1978-93, the number of excess deaths from lung cancer was approximately twice that of deaths from mesothelioma. ${ }^{12}$ Yet, in the SWORD surveillance scheme in the UK, the number of cases of mesothelioma has consistently exceeded the number of asbestos related lung cancers by almost 10:1. ${ }^{13}$ De Vos Irvine et al ${ }^{14}$ reported much the same finding for Scotland. This may suggest that chest physicians are reluctant to attribute lung cancer to asbestos in patients, most of whom are heavy smokers, without supporting evidence of asbestosis.

It is likely that any link between asbestos exposure, lung cancer, and asbestosis will be seriously complicated by questions of asbestos fibre type, smoking habit, and industrial process. It is now fairly well established that the risk of lung cancer is generally much greater after exposure to the commercial amphiboles (crocidolite and amosite) than to commercial chrysotile ${ }^{12}$ and that, for the latter, the risk is largely determined by the varying content of fibrous tremolite. ${ }^{15}$ The risk of pulmonary fibrosis, as detected by chest radiography, probably follows the same general pattern but to a far lesser degree. ${ }^{16}$ Thus, the exposure needed to cause lung cancer or mesothelioma in chrysotile workers may usually exceed that required to produce fibrosis, whereas with amphiboles the reverse may be true.

\section{CONCLUSION}

No epidemiological study is perfect, which is certainly evident in the nine papers reviewed here. The scientific question of whether or not asbestos-related lung cancer in man arises only in the presence of pulmonary fibrosis may be unanswerable epidemiologically. Microscopic evidence of fibrosis is a great deal more sensitive in detecting asbestosis than chest radiography or even high resolution computed tomography
(HRCT). Even HRCT scans may fail to detect fibrosis evident on microscopic examination, and fibrosis may have causes other than asbestos. The medicolegal question of whether fibrosis should be required-and, if so, how defined and detected-for attribution of a causal role to asbestos in relation to lung cancer is a matter for debate. This should take into account the strengths and weaknesses of the epidemiological and other medical evidence, and social considerations concerning the level of proof of causation to be required from those developing lung cancer after occupational exposure to asbestos. Much the same conclusion was finally expressed by Sluis-Cremer and Bezuidenhout:" "It should be emphasized that these results should not affect compensation bodies dealing with living subjects exposed to asbestos as slight asbestosis is commonly, and moderate asbestosis occasionally, undetected radiologically."

\section{Authors' affiliations}

P A Hessel, 546 E Delgado Dr, Palatine, IL 60074, USA

J F Gamble, 566 Elizabeth Ave, Somerset, NJ 08873, USA

J C McDonald, Department of Occupational and Environmental

Medicine, National Heart and Lung Institute, Imperial College School of Medicine, London SW3 6LY, UK

\section{REFERENCES}

1 Sluis-Cremer GK, Bezuidenhout BN. Relation between asbestosis and bronchial cancer in amphibole asbestos miners. $\mathrm{Br} \mathrm{J}$ Ind Med 1989;46:537-40

2 Sluis-Cremer GK, Bezuidenhout BN. Reply to Rudd. Br J Ind Med 1990;47:215-6.

3 Hughes JM, Weill $\mathrm{H}$. Asbestosis as a precursor of asbestos related lung cancer: results of a prospective mortality study. $\mathrm{Br} J$ Ind Med 1991;48:229-33.

4 Martischnig KM, Newell DJ, Barnsley WC, et al. Unsuspected exposure to asbestos and bronchogenic carcinoma. BMJ 1977;1:746-9.

5 Liddell FDK, McDonald JC. Radiological findings as predictors of mortality in Quebec asbestos workers. Br J Ind Med 1980;37:257-67.

6 Karjalainen A, Anttila S, Heikkila L, et al. Lobe of origin of lung cancer among asbestos-exposed patients with or without diffuse interstitial fibrosis. Scand J Work Environ Health 1993;19:102-7.

7 Anttila S, Karjalainen A, Taikina-aho O, et al. Lung cancer in the lower lobe is associated with pulmonary asbestos fiber count and fiber size. Environ Health Perspect 1993;101:166-70.

8 Hillerdal G. Pleural plaques and risk for bronchial carcinoma and mesothelioma: a prospective study. Chest 1994;105:144-50.

9 Wilkinson P, Hansell DM, Janssens J, et al. Is lung cancer associated with asbestos exposure when there are no small opacities on the chest radiograph? Lancet 1995;345:1074-8.

10 Finkelstein MM. Radiographic asbestosis is not a prerequisite for asbestosassociated lung cancer in Ontario asbestos-cement workers. Am J Ind Med 1997;32:341-8.

11 de Klerk NH, Musk AW, Glancy JJ, et al. Crocidolite, radiographic asbestosis and subsequent lung cancer. Ann Occup Hyg 1997;41(Suppl 1):134-6.

12 McDonald JC, McDonald AD. The epidemiology of mesothelioma in historical context. Eur Respir J 1996;9:1932-42.

13 Meredith SK, McDonald JC. Work-related respiratory disease in the United Kingdom, 1989-1992: a report on the SWORD project. Occup Med 1994:44:183-9.

14 De Vos Irvine H, Lamont DW, Hole DJ, et al. Asbestos and lung cancer in Glasgow and the west of Scotland. BMJ 1993;306:1503-6.

15 McDonald JC, McDonald AD. Chrysotile, tremolite and carcinogenicity. Ann Occup Hyg 1997;41:699-705.

16 McDonald JC, McDonald AD, Hughes JM. Chrysotile, tremolite and fibrogenicity. Ann Occup Hyg 1999;43:439-42. 